\title{
Pharmacological Clinical and Experimental Studies on the Effect of Alginates in the Treatment of Obesity
}

\author{
Dr. Teodora Handjieva-Darlenska, $\mathrm{MD}, \mathrm{PhD}^{1}$ \\ Department of pharmacology and toxicology, Medical Faculty, Medical University, Sofia, Bulgaria
}

\begin{abstract}
:
Introduction: In the prevention and treatment of obesity dietary regiments plays a major role. Recently the benefits of different food supplements are pointed out. The aim of our study was to examine the effect of alginates on the weight loss and body mass index (BMI), and some metabolic parameters in adults and rodents.

Materials and methods: The first study represented a clinical study. A total of 108 obese patients entered the trail. They received a diet with a $500 \mathrm{kcal} /$ daily deficit and alginates as a food supplements. Anthropometric measures were done at baseline and after 6 weeks. Lipid status was also measured. The second study was an experimental study on 48 male obese Wistar rats with previously developed nutritional model of obesity.

Results: We found statistically significant reduction of BMI and waist circumference in the group, treated with alginates. Further, total cholesterol, LDL-cholesterol and triglycerides were also statistically significantly reduced in the treated group. Our experimental study showed that rats treated with alginate acid demonstrated a significant reduction of body weight. Moreover there were changes in the blood levels of ghrelin between those treated with/without alginates.
\end{abstract}

Conclusions: Our study suggests that alginates could be useful for reduction of body weight and can reduce lipid cardiovascular risk factors in both humans and animals

\section{INTRODUCTION}

Obesity is a wide spread disease not only in the countries with high standard of living, but in the counties with lower standard. According to the Bulgarian Association for the Study of Obesity and Related Diseases (BASORD) more than $56 \%$ of adult Bulgarians are overweight $\left(\right.$ BMI $\left.>25 \mathrm{~kg} / \mathrm{m}^{2}\right)$ and $17.7 \%$ are obese (BMI $\left.>30 \mathrm{~kg} / \mathrm{m}^{2}\right)$. The treatment of obesity includes three major approaches- diet, increased physical activity and drug therapy. Drugs for treatment of obesity have to be effective in weight reduction, well tolerable and without side effects.

Obesity continues to grow steadily despite of the numerous efforts to prevent and fight it. Food supplements containing alginate acid are an approved pharmacological treatment of obesity. However, the effect of such supplements on the appetite regulation and metabolism is still unknown.

The new Bulgarian food supplement "Algigracil" consists of algine acid salts and antioxidantive complex. One dose (one sachet) contains highly purified alginates (compounds of alginic acid), Vitamin E 30mg, Vitamin C $60 \mathrm{mg}$ and beta-carotene $3 \mathrm{mg}$. Dissolved in water and taken in 20-30 sec, alginates turns in to gel in the stomach, which remains there 2-3 hours and brings forth a sense of repletion.

Aims:

A) To examine the effect of alginates on the weight loss, BMI and lipid parameters in patients with obesity;

B) To investigate possible effect of alginates on the orexigenic hormone ghrelin in obese male rats.

\section{MATerial AND Methods}

\subsection{Clinical Study}

108 patients (68 females and 40 males) with obesity were examined (mean age 37,8 year, mean BMI $-33,7 \mathrm{~kg} / \mathrm{m}^{2}$ ). Alginates were applied in dose 2 sachet t.i.d. parallel with a diet with a $500 \mathrm{kval} /$ daily deficit for 6 weeks.

${ }^{1}$ Corresponding Author: teodorah@abv.bg 
Anthropometric indexes were measured as follows - body weight $(\mathrm{kg})$ and BMI $\left(\mathrm{kg} / \mathrm{m}^{2}\right)$. The waist to hip ratio was also calculated. The percentage of the fat mass was determined by a bioimpedance apparatus Tanita 420 .

Total cholesterol, HDL-cholesterol, LDL-cholesterol and triglycerides were measured in human plasma. All tests were made at the beginning and in the end of the study.

Data were statistically analyzed by SPSS, v.16. The statistical significance was set at $\mathrm{p}<0.05$.

\subsection{Experimental Study}

A total of 48 male Wistar rats (200-220g) were used. Rats were randomized into 4 groups. In the first group, rats were fed with a standard chow diet (controls); in the second group rats were fed with standard chow plus alginates; in the third group rats were fed with a high-fat diet, containing mixture of various nuts plus standard chow food (experimental obesity); the forth group was fed with a high-fat diet, chow food and alginates. All the groups were fed for a 3-week period. Alginates were given once a day $(0.5 \mathrm{ml} / 100 \mathrm{~g})$. Food intake was determined daily; body weight was measured at the end of each 3 days. At the end of the study rat were anaesthetized and blood was collected. Epididymal fat tissue and various organs were removed and weighed. Blood specimens were taken for biochemical analyses. Plasma ghrelin concentrations were examined by ELISA methodology.

\subsection{Clinical Study}

\section{RESULTS}

After 6 weeks a reduction of body weight ( $\mathrm{kg})$, BMI, waist to hip ratio, fat mass (\%) and fat mass $(\mathrm{kg})$ was observed (Table 1).

Table 1. Changes in anthropometric and body impedance characteristics before and after the study

\begin{tabular}{|c|c|c|c|c|c|}
\hline & Body mass $(\mathrm{kg})$ & BMI & Waist to hip ratio & Fat mass \% & Fat mass $(\mathrm{kg})$ \\
\hline Before study & 94.6 & 33.12 & 0.88 & 36.2 & 34.2 \\
\hline After six weeks & $86.5^{*}$ & $30.28^{*}$ & $0.8^{*}$ & $33.3^{*}$ & $28.8^{*}$ \\
\hline
\end{tabular}

*Statistical significance was set at $\mathrm{p}<0.05$

Moreover, the results showed significant reduction in all lipid parameters (Table 2)

Table 2. Changes in lipid parameters before and after the study

\begin{tabular}{|c|c|c|c|c|}
\hline & Total cholesterol & HDL & LDL & Triglycerides \\
\hline Before treatment & 6.64 & 1.08 & 4.1 & 2.3 \\
\hline After 6 weeks & $6.02^{*}$ & $1.06^{*}$ & $3.2^{*}$ & $1.7^{*}$ \\
\hline
\end{tabular}

*Statistical significance was set at $\mathrm{p}<0.05$.

The food supplement with alginates was very well tolerated by our subjects. No side effects were reported.

\subsection{Experimental Study}

Alginates affected the development of obesity and the parameters of carbohydrate and fat metabolism in rats. A decrease of plasma lipids and glucose in groups treated with Alginates was determined. Those results correlated with a significant decrease of pancreas weight in rats. The group treated with alginate acid showed a significant reduction of body weight and BMI. Alginates reduced the weight gain (27.5\%) in the forth group (experimental obesity plus alginates), compared with the third group (experimental obesity). Moreover, there were changes in the blood levels of ghrelin between those treated with/ without alginates.

\section{DISCUSSION}

The effect of food supplements is based on the property of the compounds of alginic acid (organic acid originating from kelp) to produce gel in an acid medium (the gastric juice) which is insoluble and hard to be assimilated in to the organism. Thus, taking this kind of food supplements would reduce a further intake of high caloric foods, and would possibly promote a weight loss and a good patient's compliance towards weight maintenance.

The vitamins contained in this food supplement are properly selected and contribute to prevent degenerative vascular changes. These vitamins of highly antioxidant capacity reduce the oxidation stress level and keep the cell physiological functions.

High-fat diet led to the development of obesity in male Wistar rats. The group treated with alginate acid showed a significant reduction of body weight and adiposity. Moreover, there were changes in the blood levels of ghrelin 


\section{American Research Journal Of Medicine And Surgery, Volume 1, Issue 1, 2015 ISSN 2379-8955}

between those treated with/ without alginates. Thus, the beneficial effect of alginates on ghrelin could be possibly explained by its mechanical effect of the stomach mucosa, and thus on the ghrelin secretion.

\section{Conclusions}

After six week of treatment with alginates significant decrease of the body weight and BMI $(\mathrm{p}<0.01)$ was established in comparison to the control group. Alginates assured mechanical satiety. The food supplement showed a lack of side effects.

$>$ Our results demonstrated that alginates inhibit the development of obesity in male Wistar rats. In addition the tested Bulgarian supplement had the capacity to reduce the the blood glucose and lipid levels. The supplement assured a mechanical satiety. Moreover, the product did not present side effects in rats.

$>$ The beneficial effect of alginates on ghrelin could be possibly explained by its mechanical effect on the stomach mucosa, and thus on the ghrelin secretion.

\section{REFERENCES}

[1] Balabanski L, Handjiev Sv. Algigracile and Antigrassin in the treatment of obesity. 3rd International Congress on Obesity, Rome, 1980

[2] Birketvedt GS, Shimshi M, Erling T, Florholmen J. Experiences with three different fiber supplements in weight reduction. Med Sci Monit. 2005 Jan; 11(1):PI5-8.

[3] Handjieva-Darlenska T, Boyadjieva N. Algigracile instant - clinical and experimental data. Does it have possible effect on ghrelin? Tchudomir Nachev Symposium, Sofia, 2006

[4] Handjieva-Darlenska T, Velichkova R, Boyadjieva N. Experimental studies on the pharmacological effects of alginates. Tchudomir Nachev Symposium, Sofia, 2006

[5] Handjieva-Darlenska T, Boyadjieva N. The effects of alginates on the appetite and weight in obese rats. Obesity facts, 2014, vol. VII, supp. 1, p. 72

[6] Handjieva-Darlenska T. Clinical pharmacological study of the effect of alginates in the treatment of obesity. GP News 2014, 8-2325

[7] Handjiev Sv, Ikonomova K, Chekerdjiiski R, Nachev Ch. The new Bulgarian supplement Algigracil-Instant in the treatment of obesity. Transport Medicine 2002, vol. XXIV, 23-24

[8] Handjiev Sv, Chekerdjiiski R, Nachev Ch. The role of alginates in the treatment of obesity. First Balkan congress on obesity, Athens, 2003

[9] Kimura Y, Watanabe K, Okuda H. Effects of soluble sodium alginate on cholesterol excretion and glucose tolerance in rats. J Ethnopharmacol 1996 Oct; 54(1):47-54

[10] Odunsi ST, Vázquez-Roque MI, Camilleri M, Papathanasopoulos A, Clark MM, Wodrich L, Lempke M, McKinzie S, Ryks M, Burton D, Zinsmeister AR. Effect of alginate on satiation, appetite, gastric function, and selected gut satiety hormones in overweight and obesity. Obesity (Silver Spring). 2010 Aug; 18(8):1579-84

[11] Paxman JR, Richardson JC, Dettmar PW, Corfe BM. Daily ingestion of alginate reduces energy intake in free-living subjects. Appetite 2008 Nov;51(3):713-9

[12] Paxman JR, Richardson JC, Dettmar PW, Corfe BM Alginate reduces the increased uptake of cholesterol and glucose in overweight male subjects: a pilot study. Nutr Res 2008 Aug;28(8)

[13] Paxman JR, Richardson JC, Dettmar PW, Corfe BM. Alginate reduces the increased uptake of cholesterol and glucose in overweight male subjects: a pilot study. Nutr Res 2008 Aug; 28(8):501-5.

[14] Paxman JR, Richardson JC, Dettmar PW, Corfe BM. Daily ingestion of alginate reduces energy intake in free-living subjects. Appetite 2008 Nov;51(3):713-9

[15] Pelkman CL, Navia JL, Miller AE, Pohle RJ. Novel calcium-gelled, alginate-pectin beverage reduced energy intake in nondieting overweight and obese women: interactions with dietary restraint status. Am J Clin Nutr. 2007 Dec; 86(6):1595602

[16] Solah VA, Kerr DA, Adikara CD, Meng X, Binns CW, Zhu K, Devine A, Prince RL. Differences in satiety effects of alginate- and whey protein-based foods. Appetite 2010 Jun;54(3):485-91

[17] Solah VA, Kerr DA, Adikara CD, Meng X, Binns CW, Zhu K, Devine A, Prince RL. Differences in satiety effects of alginate- and whey protein-based foods. Appetite 2010 Jun; 54(3):485-91 